\title{
Potential Benefits of Pre-emptive PGx Testing in Male Breast Cancer Patients
}

\author{
Heather H. Randles, PharmD ${ }^{1}$; Nina Abraham, BS, PharmD²; Michael J. Schuh, BS, PharmD, MBA, FAPhA ${ }^{3}$
}

${ }^{1}$ Mayo Clinic Department of Pharmacy; ${ }^{2}$ Palm Beach Atlantic University-Lloyd L. Gregory School of Pharmacy

${ }^{3}$ Mayo Clinic Department of Pharmacy and School of Health Sciences College of Medicine

\begin{abstract}
The objective is to report a case of recurrent breast cancer in a poor CYP2D6 metabolizer male patient on tamoxifen, and how pharmacogenomic (PGX) testing can play an important role in selecting appropriate adjuvant endocrine therapy.

The case examined here is a 60-year-old white male diagnosed with recurrence of breast cancer. The patient was prescribed tamoxifen four years prior as adjuvant endocrine therapy after initial treatment with surgery. PGx testing ordered at the time of recurrence revealed patient is a poor metabolizer of CYP2D6, which may decrease the efficacy of tamoxifen. The results prompted a change in therapy to an aromatase inhibitor (Al).

This case illustrates the potential benefits of preemptive PGx testing in a male breast cancer patient to assist in selecting appropriate adjuvant therapy based on how the patient metabolizes medications. In addition, PGx testing encourages patient involvement by emphasizing the association of genetics in determining treatment. The ultimate goal in performing these tests is to individualize treatment to improve safety and efficacy while minimizing adverse drug reactions.
\end{abstract}

Keywords: CYP2D6, male breast cancer, pharmacogenomic, PGx testing, tamoxifen

\section{Introduction}

Pharmacogenomic (PGX) testing identifies genetic variants that effect medication metabolism, adverse effects, and efficacy. Results of PGx tests provide additional guidance for selecting appropriate medication treatment. Currently PGx tests are not routinely ordered in breast cancer patients. However, many medications used for treatment and supportive care have PGx dosing recommendations. ${ }^{1}$ Breast cancer is one of the more prevalent types of cancer, usually affecting females. The risk of a male patient getting breast cancer is 1 in 1000, compared to 1 in 8 for females. ${ }^{2,3}$ The key differences between breast cancer in men and women are seen in Table 1. As depicted in the table, staging for both male and female breast cancer is the same. Males that present with breast cancer generally have more estrogen receptor positive tumors, higher stage, and a lower grade. ${ }^{2}$ Due to the limited number of male breast cancer cases, treatment is based on that of female breast cancer. ${ }^{4}$ For males who present with hormone receptor positive breast cancer, adjuvant endocrine therapy with tamoxifen is recommended for five to ten years. ${ }^{5}$ Studies have shown an association between CYP2D6 poor metabolizer genotypes and increased risks of breast cancer recurrence. $., 7,8,9,10$ Controversy has

Corresponding author: Heather H. Randles, PharmD

Ambulatory Pharmacist

Mayo Clinic Department of Pharmacy

4500 San Pablo Rd, Jacksonville, FL 32256

Phone: 904-953-2021; Email: Randles.Heather@mayo.edu remained around the topic due to additional trials which did not confirm an association. ${ }^{1,11,12}$ Clinical guidelines provide dosing recommendations for tamoxifen based on CYP2D6 genotypes. ${ }^{13,14}$ For CYP2D6 poor metabolizers, the guidelines recommend using an alternative agent due to potential lack of efficacy with tamoxifen. ${ }^{13,14}$ This case emphasizes the potential benefits of preemptive PGx testing by describing a male breast cancer patient diagnosed with recurrence of breast cancer while on tamoxifen and later found to be a CYP2D6 poor metabolizer.

\section{Setting}

The practice setting is a multispecialty tertiary care clinic located in Florida. This clinic offers PGx testing, pharmacist provided PGx results consultations, medication therapy management (MTM) services, and advanced services to patients who are referred by physicians.

\section{Case Report}

The subject is a 60-year-old white male who was diagnosed with ER/PR+, HER2- breast cancer in 2014. Other listed health conditions for this patient are hyperlipidemia and hypertension; BMI is $30 \mathrm{~kg} / \mathrm{m}^{2}$. No current tobacco or alcohol use; patient is a former smoker. Current medications are listed in Table 2. His family history includes two aunts with breast cancer and a brother with pancreatic cancer. In this patient's case, the risk of having cancer increases significantly due to having a first-degree relative with cancer. ${ }^{15}$ Genetic testing was negative for pathogenic mutations. In March of 2014, surgical pathological examination found that the patient had Invasive Ductal Carcinoma grade 3 with two areas being affected. The areas measured 1.2 and $1.0 \mathrm{~cm}$ respectively. Later that year, the 
patient underwent a mastectomy and completed adjuvant radiation to the left chest wall. He was started on adjuvant endocrine therapy with tamoxifen $20 \mathrm{mg}$ daily.

In 2017, the patient returned to the physician after feeling a mass along his mastectomy scar line. He was informed of the recurrence of breast cancer in his left chest wall. Following that diagnosis, the patient transferred his cancer treatment to this location. The patient continued tamoxifen therapy, and adherence was confirmed by patient interview in which the patient stated he rarely missed doses (less than one per month). In 2018, the patient had an excisional biopsy which confirmed that the patient had a tumor consistent with recurrent breast cancer. The patient was scheduled to start chemotherapy in January 2019.

PGx testing was ordered by his oncologist to assist in selecting treatment and supportive care. When PGx test results were returned, a PGx pharmacist consult was ordered by the same oncologist to review medications, discuss the PGx results with the patient, and provide recommendations to the oncologist. PGx testing revealed that the patient is a poor metabolizer of CYP2D6 $\left(* 4 /{ }^{*} 4\right)$ and a normal metabolizer of CYP3A4. After the pharmacist reviewed the PGx test results with the patient, the pharmacist recommended to the oncologist to replace tamoxifen with an aromatase inhibitor. The physician started the patient on a leuprolide injection, a gonadotropin releasing hormone agonist ( $\mathrm{GnRHa}$ ) at the same time the patient started adjuvant radiation. GnRHa may be added to an Al in males to suppress testicular production of estrogen which is not inhibited by aromatase inhibitors., ${ }^{2,16}$ Once the patient completed radiation, he was started on letrozole, an aromatase inhibitor, for adjuvant endocrine therapy; consistent with the Clinical Pharmacogenetics Implementation Consortium (CPIC) recommendation for CYP2D6 poor metabolizers. ${ }^{13}$

\section{Discussion}

This patient case is unique in that a male patient experiences recurrent $E R / P R+$ breast cancer while taking tamoxifen and is determined to be a CYP2D6 poor metabolizer through PGX testing at the time of recurrence. Tamoxifen, a selective estrogen receptor modulator, competes with estrogen for receptors on estrogen receptor positive breast cancer cells and is extensively metabolized by multiple pathways. The primary metabolic pathway is demethylation mediated by CYP3A4 followed by oxidation mediated by CYP2D6 to endoxifen, an active metabolite. Endoxifen is approximately 100 -fold more potent than tamoxifen and greatly contributes to the efficacy of tamoxifen ${ }^{17}$ Poor CYP2D6 metabolizers have been associated with higher risk of breast cancer recurrence due to decreased efficacy of tamoxifen; however, this finding has not been consistently replicated. ${ }^{1,6-11}$ The conflicting results have been attributed to different source DNA used and varying genotyping methods which may result in inconsistent identification of CYP2D6 alleles. $^{9}$ The FDA approved a PGx section in the prescribing information of tamoxifen, stating the impact of CYP2D6 polymorphisms on the efficacy of tamoxifen is not well established. However, this is followed by a statement that poor CYP2D6 metabolizers do exhibit significantly lower endoxifen levels. ${ }^{18}$

In 2018, CPIC published the first clinical practice guideline for using CYP2D6 genotyping to guide tamoxifen therapy. ${ }^{13}$ The guideline addresses tamoxifen dosing and alternatives based on CYP2D6 genotype primarily in females. Recommendations for alternatives to standard tamoxifen doses in poor CYP2D6 metabolizers are classified as "strong" based on "high levels of evidence." ${ }^{13}$ Dosing recommendations for CYP2D6 genotypes are also available from the Dutch Pharmacogenetics Working Group. ${ }^{14}$ The majority of trials and the new guidelines have been specific to female breast cancer patients; however, a study looking at 53 male breast cancer patients with the CYP2D6*4 polymorphism (poor metabolizers) showed male individuals that were poor metabolizers also had an increased probability of breast cancer recurrence. ${ }^{10}$

As a poor CYP2D6 metabolizer, the lack of efficacy of tamoxifen is a possible contributing factor to recurrence of this patient's breast cancer. Additional factors increasing his risk for recurrence include family history of breast cancer, staging of tumor, lack of adjuvant chemotherapy at initial diagnosis, and being a former smoker. ${ }^{5}$

The patient was prescribed tamoxifen as adjuvant therapy after initial diagnosis and treatment with surgery in 2014 at a different medical center. PGx testing was not performed at that time. The testing may not have been available at that location or could have been cost prohibitive at that time. Utilizing preemptive PGx at time of initial diagnosis could have detected his poor CYP2D6 metabolizer status and directed prescribing of an alternative treatment, such as an aromatase inhibitor, which may have been more effective. An alternative to $P G x$ testing that has been proposed is adding a GnRHa to tamoxifen. Limited data is available to access efficacy of this combination. One study demonstrated enhanced estradiol suppression with addition of a GnRHa; however, clinical outcomes were not reported and the combination had an increase in adverse effects ${ }^{19}$ Another possible alternative is determining endoxifen concentration levels. ${ }^{14,20}$ However, PGx testing has the benefit of allowing appropriate treatment selection earlier in the course of therapy. In addition to determining the function of CYP2D6, PGx testing most often incorporates a panel of pharmacogenes, which can be applied to multiple medications. This is beneficial in patients requiring many different medications for cancer treatment, pain management, nausea, and other supportive care.

In this patient, PGx testing was ordered by oncology after diagnosis of recurrence to assist in drug selection for treatment and supportive care, and the pharmacist was consulted to review the results with the patient. PGx testing was performed from a buccal swab sample using a commercial laboratory, 
which utilizes polymerase chain reaction and single nucleotide polymorphism detection. The PGx test panel detects 27 genes, including 9 cytochrome P450 genes. Of note, the test detects 40 CYP2D6 alleles (Table 3). The report provides major, moderate, and minimal gene-drug interactions and provides an analysis of whether the patient is a poor, intermediate, normal, rapid, or ultra-rapid metabolizer of cytochrome P450 enzymes included. ${ }^{21}$ Once a patient undergoes PGX testing, the results may be utilized to guide medication selection. Providing pharmacist consultation services to interpret and apply PGx results may further enhance therapy selection. In the near future, with the advances in PGx testing and computer decision support software, medications prescribed through the electronic medical record will be screened for gene-drug interactions (when PGx results are available) and provide interaction alerts. However, more complex issues such as drugdrug-gene and drug-gene-gene interactions will continue to benefit from pharmacist consultation services. This will help guide the provider in selecting medications and doses that are more individualized to the patient.

\section{Conclusion}

Studying this unique case of a poor CYP2D6 metabolizer male patient with breast cancer recurrence potentially due to pharmacogenomic inability to convert tamoxifen to the active metabolite, reveals the potential benefits of PGx testing. The CPIC guideline for CYP2D6 and tamoxifen therapy highlights the recommendations for alternative medications to be used in patients that are CYP2D6 poor and intermediate metabolizers. ${ }^{13}$ PGx testing in males can provide useful information which will allow medication therapy to be tailored to the individual needs of the patient. This information enables physicians and pharmacists to collaborate to develop an individualized medication regimen that is safe and effective, with the goal of improving medication related outcomes.

Declaration of Conflicting Interests: The authors declare that there is no conflict of interest.
Abbreviations:
$\mathrm{CPIC}=$ Clinical Pharmacogentics Implementation Consortium
CYP $450=$ Cytochrome $P 450$
$\mathrm{ER} / \mathrm{PR}+=$ Estrogen Receptor/Progesterone Receptor positive
$\mathrm{GnRHa}=$ Gonadotropin Releasing Hormone agonist
HER2 = Human Epidermal Growth Factor receptor 2
MTM = Medication Therapy Management
Pharmacogenomic $=P G x$

\section{References}

1. Zhang $Y$, Somtakoune SD, Cheung, C, et al. Therapeutic Application of Pharmacogenomics in Oncology. AAPSJ. 2016; 18(4):819.

2. Giordano SH. Breast cancer in men. N Engl J Med. 2018; 378:2311-2320.

3. Key statistics for breast cancer in men: cancer facts and figures 2019. Atlanta: American Cancer Society; [updated 2019 Jan 8; cited 2019 Oct 25]. Available from: https://www.cancer.org/cancer/breast-cancerin-men/about/key-statistics.html.

4. Anderson WF, Jatoi I, Tse J, et al. Male breast cancer: a population-based comparison with female breast cancer. J Clin Oncol. 2010 Jan 10; 28(2):232-9.

5. Brown K. Male breast cancer treatment and prognosis [Internet]. Baltimore (MD): Johns Hopkins Breast Center; [updated 2019; cited 2019 Oct 25]. Available from:

https://www.hopkinsmedicine.org/breast_center/breast_ cancers_other_conditions/breast_cancer_in_men.

6. Schroth W, Antoniadou L, Fritz P, et al. Breast Cancer Treatment Outcome With Adjuvant Tamoxifen Relative to Patient CYP2D6 and CYP2C19 Genotypes. J Clin Oncol. 2007; 33:5187-5193.

7. Province, MA, Goetz MP, Brauch $\mathrm{H}$, et al. CYP2D6 genotype and adjuvant tamoxifen: meta-analysis of heterogeneous study populations. Clin. Pharmacol Ther. 2014; 95:216-227.

8. Regan M, Leyland-Jones B, Bouzyk M, et al. CYP2D6 Genotype and Tamoxifen Response in Postmenopausal Women with Endocrine-Responsive Breast Cancer: The Breast International Group 1-98 Trial, JNCl: J Natl Cancer Institute. 2012; 104(6):441-451

9. Drogemoller B, Wright G, Shih J, et al. CYP2D6 as a treatment decision aid for ER-positive non-metastatic breast cancer patients: a systematic review with accompanying clinical practice guidelines. Breast Cancer Res Treat. 2019;173(3):521-32.

10. Abreu MH, Gomes M, Menezes F et al. CYP2D6*4 polymorphism: A new marker of response to hormonotherapy in male breast cancer? Breast. 2015 Aug; 24(4):481-6.

11. Sanchez-Spitman A, Dezentje V, Swen J, et al. Tamoxifen pharmacogenetics and metabolism: Results from the prospective CYPTAM Study. J Clin Oncol.2019;37(8):636-46.

12. Hertz DL, Kidwell KM, Hilsenbeck SG, et al. CYP2D6 genotype is not associated with survival in breast cancer patients treated with tamoxifen: results from a population-based study. Breast Cancer Res Treat. 2017;166(1):277-87. 
13. Goetz M, Sangkuhl K, Guchelaar H, et al. Clinical Pharmacogenetics Implementation Consortium (CPIC) Guideline for CYP2D6 and Tamoxifen Therapy. Clin Pharmacol Ther. 2018; 103(5):770-777.

14. Tamoxifen guideline annotations PharmGKB.org[Internet]. Stanford (CA): PharmGKB; [updated 2019; cited Oct 10]. Available from: https://www.pharmgkb.org/chemical/PA451581/guid elineAnnotation

15. Male breast cancer treatment. National Cancer Institute. [updated 2019 May 22; cited 2019 Oct 5] http://www.cancer.gov/types/breast/patient/malebreast-treatment-pdq.

16. Di Lauro L, Pizzuti L, Barba M, et al. Role of gonadotropin-releasing hormone analogues in metastatic male breast cancer: results from a pooled analysis. J Hematol Oncol. 2015; 8:53. doi:10.1186/s13045-015-0147-z.

17. Lim YC., Desta, Z, Flockhart, DA \& Skaar, TC. Endoxifen (4-hydroxy-N-desmethyl-tamoxifen) has anti-estrogenic effects in breast cancer cells with potency similar to 4-hydroxy-tamoxifen. Cancer Chemother Pharmacol.2005; 55:471-478.

18. Product Information: SOLTAMOX(R) oral solution, tamoxifen citrate oral solution. Midatech Pharma US Inc (per FDA), Raleigh, NC, 2018.

19. Reinisch M, Seiler S, Hauzenberger T et al. Final analysis of the Male-GBG54 study: A prospective, randomised multi-centre phase II study evaluating endocrine treatment with either tamoxifen +/gonadotropin releasing hormone analogue ( $\mathrm{GnRHa})$ or an aromatase inhibitor $+\mathrm{GnRHa}$ in male breast cancer patients. Ann Oncol. 2018; 29(8):supp. doi:10.1093/annonc/mdy424.007

20. Madlensky L, Natarajan L, Tchu S et al. Tamoxifen Metabolite Concentrations, CYP2D6 Genotype and Breast Cancer Outcomes. Clin Pharmacol Ther. 2011 May; 89(5): 718-725.

21. OneOme Labs.Minneapolis (MN). [cited 2019 Oct 5]. Available from https://oneome.com. 
Table 1: Differences in Male and Female Breast Cancer

\begin{tabular}{|c|c|c|}
\hline Subtype (\%) & Male & Female \\
\hline HR+, HER2- & 90 & 71 \\
\hline HR +, HER2 + & 9 & 12 \\
\hline HR-, HER2 + & $<1$ & 12 \\
\hline HR-, HER2- & $<1$ & Female \\
\hline 5-yr overall survival (\%) & Male & 90 \\
\hline Stage I & 87 & 57 \\
\hline Stage II & 74 & 19 \\
\hline Stage III & 57 & Female \\
\hline Stage IV & 16 & Selected patients \\
\hline Treatment & Male & Tamoxifen, Aromatase Inhibitor, \\
Ovarian Suppression (pre- \\
\hline Genetic counseling
\end{tabular}

* HER=human epidermal growth factor receptor $\mathrm{HR}=$ hormone receptor

Giordano, SH. NEJM. 2018; 378:2311-2320² 
Table 2: Current Medications

\begin{tabular}{|c|c|c|}
\hline Medications/dose & Indication & $\begin{array}{l}\text { Pharmacogenomic } \\
\text { (Relevance/protein) }\end{array}$ \\
\hline $\begin{array}{c}\text { Buspirone (Buspar }{ }^{\circledR} \text { ) } 15 \text { mg mouth } \\
\text { two times a day }\end{array}$ & Anxiety & $\begin{array}{l}\text { S/CYP3A4 } \\
\text { S/CYP3A5 }\end{array}$ \\
\hline $\begin{array}{c}\text { Cyanocobalamin (Vitamin B-12 }{ }^{\circledR} \text { ) } \\
2,500 \mathrm{mg} \text { by mouth daily }\end{array}$ & Anxiety & No PGx application \\
\hline $\begin{array}{c}\text { Docusate sodium (Colace }{ }^{\circledR} \text { ) } 100 \\
\text { mg by mouth two times a day }\end{array}$ & Constipation & No PGx application \\
\hline $\begin{array}{c}\text { Losartan }\left(\text { Cozaar }^{\circledR}\right) 100 \mathrm{mg} \text { by } \\
\text { mouth daily }\end{array}$ & Hypertension & $\begin{array}{l}\text { S/CYP2C9 } \\
\text { S/CYP3A4 } \\
\text { S/CYP3A5 }\end{array}$ \\
\hline $\begin{array}{l}\text { Ondansetron (Zofran }{ }^{\circledR} \text { ) } 4 \mathrm{mg} \text { by } \\
\text { mouth }\end{array}$ & Nausea & $\begin{array}{c}\text { S/CYP2D6 } \\
\text { No PGx application }\end{array}$ \\
\hline $\begin{array}{c}\left.\text { Pravastatin (Pravachol }{ }^{\circledR}\right) 20 \mathrm{mg} \text { by } \\
\text { mouth }\end{array}$ & Hyperlipidemia & S/SLCO1B1 \\
\hline $\begin{array}{c}\text { Prednisone (Deltasone }{ }^{\circledR} \text { ) } 5 \text { mg by } \\
\text { mouth }\end{array}$ & Inflammation & No PGx application \\
\hline $\begin{array}{l}\text { Sulfasalazine (Azulfidine }{ }^{\circledR} \text { ) } 500 \mathrm{mg} \\
\text { tabs } \\
\text { Take } 1,000 \mathrm{mg} \text { ( } 2 \text { tablets) by } \\
\text { mouth three times a day }\end{array}$ & Rheumatoid arthritis & No PGx application \\
\hline $\begin{array}{l}\text { Tamoxifen (Nolvadex }{ }^{\circledR} \text { ) } 20 \text { mg by } \\
\text { mouth daily }\end{array}$ & Breast cancer & $\begin{array}{c}\text { S/CYP3A } \\
\text { S/CYP2D6 } \\
\text { S/CYP2C9 } \\
\text { S/CYP2C19 } \\
\text { S/CYP2B6 } \\
\text { S/SULT1A1 } \\
\text { S/UGT2B7 } \\
\text { S/UGT1A4 }\end{array}$ \\
\hline $\begin{array}{l}\text { Ascorbic acid (Vitamin C) } 1000 \mathrm{mg} \\
\text { daily }\end{array}$ & Immune Support & -- \\
\hline Super B complex & Supplementation & -- \\
\hline $\begin{array}{c}\text { Zinc acetate } \\
\text { Take one tablet by mouth }\end{array}$ & Supplementation & -- \\
\hline \multicolumn{3}{|c|}{$\begin{array}{l}\text { *Unless otherwise noted. } \\
\text { Abbreviations: } A D R s=a d v e r s e \text { drug reaction, } B B W=\text { black box warning, } B G=\text { blood glucose, } C B C=\text { complete blood } \\
\text { count, } F D A=\text { food and drug administration, } I M=\text { intramuscular, } L F T=l i v e r \text { function test, } N / V=\text { nausea and vomiting, } \\
\text { RBC= red blood cell, } S C=\text { subcutaneous }\end{array}$} \\
\hline
\end{tabular}

Table 3: CYP2D6 Tested Alleles ${ }^{21}$

CYP 2D6

$* 2 \mathrm{~A}, * 2, * 3, * 4, * 4 \mathrm{~J}, * 4 \mathrm{M}, * 4 \mathrm{~N}, * 5, * 6, * 6 \mathrm{C}, * 7, * 8, * 9$,

*10, *11, *12, *13, *14A, *14B, *15, *17, *18, *19,

*29, *31, *34, *35, *36, *39, *41, *42, *59, *61 